\title{
ANALYSIS OF GROUND REFLECTION OF JET NOISE OBTAINED WITH VARIOUS MICROPHONE ARRAYS OVER AN ASPHALT SURFACE
}

by J. H. Miles

Lewis Research Center

Cleveland, Ohio 44135

TECHNICAL PAPER to be presented at Eighty-ninth Meeting of the Acoustical Society of America Austin, Texas, April 8-11, 1975

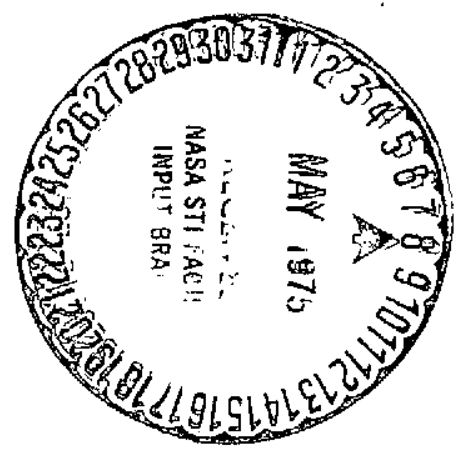




\author{
ANALYSIS OF GROUND REFLECTION OF JET NOISE OBTAINED \\ WITH VARIOUS MICROPHONE ARRAYS OVER AN ASPHALT SURFACE \\ by J. H. Miles \\ Lewis Research Center \\ National Aeronautics and Space Administration \\ Cleveland, Ohio
}

\begin{abstract}
Ground reflection effects'on the propagation of jet noise over an asphalt surface are discussed for data obtained using a $33.02 \mathrm{~cm}$ (13-in.) diameter nozzle with microphones at several heights and distances from the nozzle axis.

Analysis of ground reflection effects is accomplished using the concept of a reflected signal transfer function which represents the influence of both the reflecting surface and the atmosphere on the propagation of the reflected signal in a mathematical model. The mathematical model used as a basis for the computer program was successful in significantly reducing the ground reflection effects. The range of values of the single complex number used to define the reflected signal transfer function was larger than expected when determined only by the asphalt surface. This may indicate that the atmosphere is affecting the propagation of the reflected signal. more than the asphalt surface. Also discussed is the selective placement of the reinforcements and cancellations in the design of an experiment to minimize ground reflection effects.
\end{abstract}




\section{INTRODUCTION}

Acoustic data taking programs for experimental reseâtch on aiticiaft noise reduction using ground facilities often have problems involving interpretation of data because of ground reflectlons. Acoustic reflections from the ground cause problems, since in some experiments, reflections distort the true sound spectrum and this can lead to incorrect conclusions about spectral shapes and overestimation of the overall sound pressure level (OASPL) relative to the free field OASPL. This is particularly evident with large-scale and full scale test rigs where, due to the source/ microphone geometry, the peak sound pressure level (SPL) values in the spectra can be in the midst of that part of the spectrum where the magnitude of the distortion caused by the interference of the direct and reflected pressure wave is a maximum and the resulting cancellations and reinforcements of the pressure wave are strongest.

Many different microphone arrangements have been used at NASA Lewis acoustic test facilities. Experience shows that centerline horizontal microphone arrays of the order of 1.22 to $3.66 \mathrm{~m}$ (4 to 12 feet) above the ground are subject to such ground reflection problems. If ground microphones are used, subject to certain environmental conditions (such as the absence of temperature inversions) being met, the low frequency acoustic data are not subject to ground reflection reinforcements and cancellations; However the high frequency regions may be subject to ground reflection problems. Overhead-boom microphone array have also been used with and without ground treatment to reduce ground reflection problems. The use of such a 
boom is generally prohibitive for large or full-scale engine tests because of the 30,48-60.96 m (100-200 foot) microphone radius necessary to measure the engine nosie.

Considerable effort has gone into experimental and theoretical investigation aimed at minimizing reflection effects. Early work at NASA Lewis (ref. 1) has served as the theoretical basis for much succeeding work (refs. 2 to 4). The investigations of references 1 and 4 provide understanding of the effect of a change in microphone geometry on the measured data for many idealized cases. However, experience in the study of broadband jet noise at NASA Lewis has shown that the direct application of the results from the theoretical and experimental studies described in references 1 and 4 to practical non-ideal cases can cause difficulties. In many cases, the correction based on the studies of references 1 and 4 would lead to a more distorted spectral shape than the one measured,

The present paper discusses acoustic spectral data from cold-flow nozzles taken with microphone arrays at a variety of distances and heights above an asphalt surface. A method of analysis is then applied to these data to account for the ground reflection problems in the data. The method calculates the lossless spectra from the measured data. In addition, the reverse is also possible; i.e. the "rig" spectrum can be predicted from a free field spectrum. This makes possible selective placement of reinforcements and cancellations by using the computer method to identify desirable microphone positions. Necessary analytical expressions and procedures based on earlier work are included. 
The paper will first present the equations used to model the jet broadband spectrum and the ground reflection. The calculation method will then be discussed. Finally a comparison of this approach with experimental data will be presented.

\section{ANALYSIS}

\section{Simulation of Measured Spectrum}

The present analysis considers a mathematical model for the measured broadband subsonic jet noise third octave sound pressure level (SPL) spectrum generated by a convergent nozzle over an asphalt surface.

A schematic of the nozzle microphone geometry relative to the asphalt is shown in figure 1 . The parameters in this model can be adjusted so that the resulting calculated spectra is a least square fit to the measured spectra. From the model the following are achieved: (1) corrections are obtained that enable the calculation of the lossless spectrum from the measured data and (2) an equation for a smooth least square curve fit to the lossless spectrum is generated.

The equation representing the SPL spectrum are written as the sum of a lossless third octave spectrum level, $\mathrm{SPL}^{+}$, a ground reflectance, $|\mathrm{T}|^{2}$, and an atmospheric attenuation level, $A$. Thus, in $d B$

$$
\mathrm{SPL}_{\mathrm{cal}}=\mathrm{SPL}_{\mathrm{ca} 1}^{+}+10 \log _{10}|\mathrm{~T}|^{2}+\mathrm{A}
$$

referenced to a pressure $\mathrm{P}_{\mathrm{r}}$ where 


$$
\mathrm{pr}_{\mathrm{r}}=2 \times 10^{-5} \text { Pascal }\left(2 \times 10^{-4} \mu \text { bar }\right)
$$

(All symbols are defined in the Symbol List Appendix A.)

The method of analytically representing the lossless SPL spectra, $\mathrm{SPL}_{\text {cal }}^{+}$used herein was briefly described in reference 2 and presented in reference 3 in more detail. The necessary equations used herein from these references are presented in Appendix B. Briefly, the $\mathrm{SPL}_{\mathrm{cal}}^{+}$in any third octave band is determined from: (1) an overall sound pressure level value; (2) an effective diameter, $\mathrm{D}_{e}$, and an effective velocity, $\mathrm{V}_{\mathrm{e}}$, used with frequency to determine the Strouhal number, St, $\left(S t=f D_{e} / V_{e}\right)$; and (3) a pressure spectral density level curve, $\mathrm{PSD}_{\mathrm{cal}}^{+}$, which is a function of Strouhal number and which is normalized to have unit area. Thus

$$
\mathrm{SPL}_{\mathrm{cal}}^{+}=10 \log _{10} \quad 10^{\mathrm{OASPL}_{\mathrm{p}}^{+} / 10} \Delta \mathrm{f}_{\mathrm{c}} \frac{\mathrm{D}_{\mathrm{e}}}{\mathrm{V}_{\mathrm{e}}}+\mathrm{PSD}_{\mathrm{cal}}^{+}
$$

The ground reflectance, $|\mathrm{T}|^{2}$, is determined by two factors. The first factor is the complex reflected signal transfer function written in terms of its magnitude $Q(s)$ and its phase $\delta(s)$ as

$$
G(s)=Q(s) e^{j \delta(s)}
$$

where $s$ is the Laplace transform variable $(s=j 2 \pi f)$. The second factor is the microphone and test site geometry (fig. 1).

The model used to take account of the effect of microphone and test site geometry assumes that the nolse source is distributed over a region 
and represents this by taking into account signals from $N$ independent sources. This model creates a spectrum dependent on a range of time delays. The time delays are calculated by assuming the $\mathrm{N}$ sources are distributed vertically about the centerline at the nozzle exit. This assumption was used to study acoustic interference of the noise produced by a single jet due to reflections from a surface (ref. 4) and in references 2 and 3 to study acoustic interference of flap noise due to reflection from a surface.

The equation for the ground reflectance for third octave spectra taken from references 2 and 3 , is given by

$$
\left|T\left(f_{c}\right)\right|^{2}=1+\frac{Q^{2}\left(f_{c}\right)}{z^{2}}+\frac{2}{N} \frac{Q}{z}\left(f_{c}\right) \sum_{n=1}^{N} \cos \left[2 \pi f_{c} \tau_{n}-\delta\left(f_{c}\right)\right] \frac{\sin \pi \Delta f_{c} \tau_{n}}{\pi \Delta f_{c} \tau_{n}}
$$

where the functional dependence of $Q$ and $\delta$ has been changed from the Laplace transform variable $s$ to $f_{c}$ to indicate that $Q$ and $\delta$ are assumed constant over a third octave band having center frequency, $f_{c^{\circ}}$

In equation ( 3 ) the time delay, $\tau_{n}$, between the reflected and direct pressure signal is given by

$$
\tau_{n}=\frac{s_{2}(n)-s_{1}(n)}{c_{0}}
$$

The symbol $z$ is the mean value of the ratio of the reflected signal travel distance to the direct signal travel distance given by

$$
z=\frac{s_{2}(n)}{s_{1}(n)}=\frac{\left\{r^{2}+\left[h_{s}(n)+h_{0}\right]^{2}\right\}^{\frac{1}{2}}}{\left\{r^{2}+\left[h_{s}(n)-h_{0}\right]^{2}\right\}^{1 / 2}}
$$


Empirical formulas for computing the atmospheric attenuation level $A\left(f_{c}, r\right)$ can be found in references 5 and 6 . The data reported in this paper were corrected using the atmospheric attenuation level calculated by the method of reference 6 .

Reflected Signal Transfer Function

The reflected signal transfer function, $G(s)$, is used to represent the effect of reflections and it arises as follows. The reflected signal is assumed to be related to the direct signal by a convolution integral of an 1mpulse response with the direct pressure signal. This impulse response represents the effects of both the reflecting surface and the atmosphere on the propagation of the reflected signal. The Laplace transform of this impulse response is the reflected signal transfer function, G(s), (eq. (2)). This approach is presented in more detall in references 2 and 3.

The magnitude, $Q\left(f_{c}\right)$, and phase $\delta\left(f_{c}\right)$ of the reflected signal transfer function, $G\left(f_{c}\right)$, must be specified in order to calculate the reflectance, $\left|T\left(f_{c}\right)\right|^{2}$. Neglecting atmospheric effects the value of the reflected ray transfer function has been determined from physical assumptions concerning the nature of the acoustical signal i.e. plane wave or spherical wave and the nature of the boundary at the relevant surfaces i.e. scattering from a rough surface, absorption by an infinite surface, or a multilayer surface. However, realistic (i.e. non-plane wave) mathematical models cannot be solved exactly and always requires approximations.

The empirical approximation found most useful in specifying $G\left(f_{c}\right)$ was to assume that $Q\left(f_{c}\right)$ and $\delta\left(f_{c}\right)$ are constant over the frequency range of 
interest. Thus

$$
G=Q e^{j \delta}
$$

A discussion of this approximation follows. The reflected signal transfer function, $G\left(f_{c}\right)$, has not been related to any physical model in the previous sections. However if the surface material can be characterized by a complex ground surface impedance $z_{2}$ and a speed of sound $c_{2}$, then neglecting atmospheric effects, $G$ is the plane wave reflection coefficient, $C_{R}$,

$$
C_{R}=\frac{z_{2} \cos \theta_{1}-z_{1} \cos \theta_{2}}{Z_{2} \cos \theta_{1}+z_{1} \cos \theta_{2}}=G=Q e^{j \delta}
$$

where

$$
\frac{\sin \theta_{1}}{c_{o}}=\frac{\sin \theta_{2}}{c_{2}}
$$

and

$$
z_{1}=\rho c_{0}
$$

and the plane wave is incident at an angle $\theta_{1}$ to the normal of the surface (refs. 7,8 ).

For a spherical wave the same reflection coefficient is applicable for source-microphone distances much larger than 3 wavelengths. This is shown for the analogous electromagnetic case (ref. 9). This result as applied to the acoustic problem was previously discussed in reference 10 and used in reference 11 . Reference 11 also discussed the general spheri- 
cal wave reflection problem using results of the analogous electromagnetic case obtained in reference 12 .

The ground absorption coefficient $\alpha_{g}$ is related to the reflection coefficient by

$$
\alpha_{g}=1-\left|\mathrm{C}_{\mathrm{R}}\right|^{2}
$$

Thus, the square of the magnitude of the reflected signal transfer function is related to the absorption coefficient by

$$
\left|G\left(f_{c}\right)\right|^{2}=|Q|^{2}=\left|C_{R}\right|^{2}=1-\alpha_{g}
$$

Hence, assuming that $|G(s)|^{2}$ is independent of frequency corresponds to assuming that the absorption coefficient $\alpha_{g}$ is also independent of frequency.

The author is not aware of data supporting the assumption that $Q\left(f_{c}\right)$ and $\delta\left(f_{c}\right)$ are constant over the frequency range of interest for asphalt surfaces. However impedance tube measurements by Dickinson and Doak of the normal absorption coefficient of sharp sand over a frequency range from 200 to 1000 hertz for a moisture content ranging from 0 to 10 percent indicated the normal absorption coefficient was not strongly dependent on frequency at a given moisture content (ref. 13).

Although it is not known if asphalt behaves IIke sharp sand, the assumption will be made as a necessary part of the procedure that $Q\left(f_{c}\right)$ and $\delta\left(f_{c}\right)$ are constant over the frequency range of interest. 


\section{Determination of Lossless Spectrum}

The lossless spectrum is calculated by curve fitting equation (1) to measured data by adjusting the parameters that determine $|T|^{2}$ and $\mathrm{SPL}_{\mathrm{cal}}^{+}$. A least square fit to the lossless sound pressure level is then given by equation (B-1) for $\mathrm{SPL}_{\mathrm{Cal}}^{+}$.

The lossless sound pressure level can also be calculated by subtracting the atmospheric attenuation level and the reflectance from the measured data. Thus

$$
\mathrm{SPL}_{\mathrm{m}}^{+}=\mathrm{SPL}_{\mathrm{ID}}-10 \log _{10}|\mathrm{~T}|^{2}-\mathrm{A}
$$

Another procedure for obtaining lossless spectra is to use ground microphones. For a microphone on the ground the time delays are close to zero since the reflected signal path differs very little from the direct signal path. Thus from equations (3), (4), and (5), over a large frequency range,

$$
\left|T\left(f_{c}\right)\right|^{2} \simeq(1+Q)^{2}
$$

and the reflectance is independent of frequency. The maximum value of $Q$ is 1 . For this value of $Q$,

$$
10 \log _{10}\left|\mathrm{~T}\left(\mathrm{f}_{\mathrm{c}}\right)\right|^{2}=6 \mathrm{~dB}
$$

Thus, if the value of $Q$ is 1 , the lossless spectrum could be calculated from a ground microphone measured spectrum over a large frequency range by 


$$
\mathrm{SPL}_{\mathrm{m}}^{+}=\mathrm{SPL}_{\mathrm{m}}-6 \mathrm{~dB}-\mathrm{A}
$$

For a surface characterized by a complex impedance $Z_{2}$ much larger than the impedance of air $\left(Z_{I}=\rho c_{0}\right)$ equation (7) indicates that $Q$ will be 1 , and equation (15) can be used to calculate the lossless spectrum from a ground microphone measured spectrum.

\section{CALCULATION METHOD}

The complete equation used to simulate the SPL at a microphone is found by substituting into equation ( 1 ) equations $(B-1),(B-3)$, and (3). Thus the analytical representation is

$$
\begin{aligned}
& \mathrm{SPL}_{\mathrm{cal}}=10 \log _{10} 10^{\mathrm{OASPL}}+\frac{\mathrm{p}}{\mathrm{c}} \mathrm{f}_{\mathrm{e}} \frac{\mathrm{D}_{\mathrm{e}}}{\mathrm{V}_{\mathrm{e}}} \\
& +c_{0}+\sum_{i=1}^{M_{d}} E\left[u(i), \eta_{p}(i)\right]-\sum_{k=1}^{N_{b}} E\left[u(k), \eta_{p}(k)\right] \\
& +10 \log _{10}\left[1+\frac{Q^{2}}{z^{2}}+\frac{2}{N} \frac{Q}{z} \sum_{n=1}^{N} \cos \left(2 \pi f_{c} \tau_{n}-\delta\right) \frac{\sin \left(\pi \Delta f_{c} \tau_{n}\right)}{\pi \Delta f_{c} \tau_{n}}\right]+A\left(f_{c}, r\right)
\end{aligned}
$$

A computer program is used to iteratively adjust the parameters OASPL $_{p}^{+}, C_{O}, S t_{p}(i), \eta_{p}(i) S t_{p}(k), \eta_{p}(k)$ which determine the spectral shape and the parameters $Q$ and $\delta$ with determine the ground reflectance. A diagram of the method is shown in figure 2. The calculation method is described briefly in reference 2 and presented in more detail in reference 3. 
The parameters are adjusted to minimize the total "cost", $C_{T}$, consisting of the sum of the squares of the differences between measured and calculated SPL values, $C_{e}$, and a "penalty cost", $C_{p}$, (refs. 14 and 15) due to selection of parameters that violate the parameter constraints. (See eq. (B-2) for OASPL ${ }_{p}^{+}$constraint.) The total "cost" function is nonlinear. The problem of minimizing the nonlinear "cost" function was solved by search techniques. These nonlinear minimization techniques consist of systematic procedures for varying the "cost" function parameters until a minimum value of the "cost" function is found. The basic nonlinear minimization methods available are discussed in references 14 and 15 . To provide flexibility in the choice of $M_{a}$ and $N_{b}$ and due to the presence of parameter constraints, a search technique which does not require evaluation of derivatives was chosen. The nonlinear minimization search technique was that of Powe1l (ref. 16). The nonlinear minimization computer program used was adapted from reference 17 . The optimization procedure was previously applied successfully to a similar identification problem in references 18 and 23 .

The input information for the method consists first of the constants required for the reflection model. These consist of the following: the number of sources $N$, the mean value of the ratio of the distance the reflected ray travels to the distance the direct ray travels, $z$; and the time delay $\tau_{n}$ associated with each of the $N$ sources. The number of time delays, $N$, was selected empirically to be 5 because for the range of time delay values used increasing the number of delays beyond five had no further effect on the third octave spectrum. 
Second, the constants $\mathrm{M}_{\mathrm{a}}$ and $\mathrm{N}_{\mathrm{b}}$ for the $\mathrm{PSD}_{\mathrm{cal}}^{+}$model are needed (see ref. 3). For the data considered, $N_{b}$ was selected to be 2 and $M_{a}$ was selected to be 1 . Last, initial values of the following parameters are necessary.

$$
\mathrm{OASPL}_{\mathrm{p}}^{+}, \mathrm{C}_{\mathrm{o}}, S t_{\mathrm{p}}(i) \text { and } \eta_{\mathrm{p}}(i) ; i=1, S t_{p}(\mathrm{k}) \text { and } \eta_{\mathrm{p}}(\mathrm{k}) ; \mathrm{k}=1,2 ; \mathrm{Q} \text { and } \delta
$$

Procedures for selecting initial values are discussed in reference 3.

The computer output is the final values of these parameters. Using the parameters $\mathrm{OASPL}_{\mathrm{p}}^{+}, \mathrm{C}_{\mathrm{o}}$, St $\mathrm{p}_{\mathrm{p}}(\mathbf{i})$ and $\eta_{\mathrm{p}}(1) ; i=1, S t_{\mathrm{p}}(\mathrm{k})$ and $\eta_{\mathrm{p}}(\mathrm{k})$;

$k=1,2$ in equation $(B-1)$ and $(B-3)$ the lossless spectrum $S P L+c a 1$ can be computed. From the value of the atmospheric attenuation and using the reflectance parameters $Q$ and $\delta$ in equation (3) the lossless spectrum $\mathrm{SPL}_{\mathfrak{m}}^{+}$can be computed from equation (12).

\section{APPARATUS}

Noise tests were conducted with a $33.02 \mathrm{~cm}$ (13 inch) diameter circular convergent nozzle having the nozzle centerline $3.89 \mathrm{~m}$ (12 $3 / 4$ feet) above grade. For this rig, dry cold air (at about $520^{\circ}$ R) was supplied to a $40.64 \mathrm{~cm}$ (16-inch) diameter gate valve from the Center's $862 \mathrm{kPa}$ (125 psia) air supply system by way of a $60.46 \mathrm{~cm}$ (24-inch) diameter underground pipe 1ine. Details of the flow and muffler systems are given in reference 19.

The noise data were measured with sixteen $1.27 \mathrm{~cm}$ condenser microphones with windscreens located as shown in Table I. The microphones were 
arranged to be approximately $145^{\circ}$ from the nozzle inlet at a radial distance of $7.62,15.24$, and $22.86 \mathrm{~m}(25,50$, and 75 feet) from the nozzle exit. The mikes near the surface were thus moved closer to the nozzle and at larger angles at the 7.62 and $15.24 \mathrm{~m}$ (25 and 50 feet) radius.

The air flow rate was measured by an orifice flowmeter located in a straight section of the underground air supply line upstream of the gate shutoff valve. Pressure drop across the orifice flowmeter and static pressure upstream of the flowmeter were measured by strain-gage pressure transducers. Strain-gage pressure transducer were also used to measure total and static pressure upstream of the nozzle. All pressures were recorded on strip-chart instruments.

Weather data were also monitored and/or recorded (i.e. barometer, temperature, humidity, wind speed and direction).

The noise data were analyzed on-1ine with an automated 1/3-octave band spectrum analyzer. The analyzer determined sound pressure level spectra (referenced to $2 \times 10^{-5} \mathrm{P}_{\mathrm{a}}(0.0002$ microbar)) between 50 and $20,000 \mathrm{~Hz}$ at each microphone position. Three noise samples were taken at each microphone and treated to reject background disturbances and random errors and to obtain an average value.

Noise measurements were made for a series of nominal nozzle pressure ratios. These were $1.1,1.2,1.3,1.4,1.5,1.7,1.8,2.0$, and 2.1 . The static pressure in the free jet stream was assumed to be atmospheric, and the the total temperature was assumed to be the same as the temperature measured upstream of the nozzle. Jet exhaust velocities were calculated from the isentropic equations. 
The test procedure was to obtain a steady flow condition for a given total pressure upstream of the nozzle. Noise data were then taken at each microphone location in succession. After three complete acoustic measurement cycles the airflow rate was changed and the process repeated.

\section{RESULTS AND DISCUSSION}

\section{Sample Results}

The computer calculation procedure provides the three major quantities that are added together as indicated by equation (1) to calculate the spectrum, SPL cal. The computer calculation method selected the parameters $\left(\mathrm{OASPL}_{\mathrm{p}}^{+}, \mathrm{C}_{\mathrm{O}}, \mathrm{St}_{\mathrm{p}}(\mathrm{i})\right.$ and $\eta_{\mathrm{p}}(i) ; i=1 ; \mathrm{St}_{\mathrm{p}}(\mathrm{k})$ and $\eta_{\mathrm{p}}(\mathrm{k}) ; \mathrm{k}=1,2 ; \mathrm{Q}$ and $\left.\delta\right)$ thereby adjusting equation (16) such that the shape of the SPL cal spectrum is in good agreement with the measured data, $S_{\mathrm{m}}$.

Figure 3 shows typical results obtained by applying the computer method described herein to the data. This data and all following data are from the $33.02 \mathrm{~cm}$ (13 inch) diameter conical nozzle operating at exhaust velocity of $301 \mathrm{~m} / \mathrm{sec}(988 \mathrm{ft} / \mathrm{sec})$. The microphones were at a nominal directivity angle of $145^{\circ}$ from the nozzle inlet.

A measured spectrum is compared with a computer calculated spectra in figure 3(a). Figure 3(a) also shows the calculated lossless spectrum, $\mathrm{SPL}_{\mathrm{cal}}^{+}$, which as indicated prevtously is based on a least square curve fit to the measured data. However while it is a smooth curve (since it takes into consideration all the data and is based on a specific formula for the spectrum), the resulting spectrum shape can have sections which do not have 
the smooth convex curve shape conventionally associated with fet noise spectra.

In order to obtain a spectrum which has an unbiased shape, it is useful to calculate a lossless spectrum, $\mathrm{SPL}_{\mathfrak{m}}^{+}$, by applying the calculated ground reflection correction and the atmospheric attenuation correction to the measured spectrum data as indicated by equation (12). However, the resulting curve is in general not smooth. Figure 3(b) compares calculated analytical lossless spectrum $\mathrm{SPL}_{\mathrm{cal}}^{+}$and calculated measured lossless spectrum $\mathrm{SPL}_{\mathrm{m}}^{+}$from the measured data shown in figure $3(\mathrm{a})$.

A SPL ${ }^{+}$curve smoothed by fairing a curve to either the $\mathrm{SPL}_{\mathrm{cal}}^{+}$or the $\mathrm{SPL}_{\mathrm{m}}^{+}$curve of figure $3(\mathrm{~b})$ is shown in figure $3(\mathrm{c})$ along with the $\mathrm{SPL}_{\text {cal }}^{+}$ curve and $\mathrm{SPL}_{\mathrm{m}}^{+}$curve, Fairing to the $\mathrm{SPL}_{\mathrm{cal}}^{+}$curve may be done to remove any bias in the least square curve fit due to (1) selection of the functional form equations and/or (2) the limited number of parameters used to curve fit with. Fairing to the $\mathrm{SPL}_{\mathrm{m}}^{+}$curve may be done to remove irregularIties introduced or not removed by the calculated reflectance and/or to remove other irregularities thought to be present in the data.

In figure 3(d), the final lossless spectrum curve, $\mathrm{SPL}^{+}$, obtained by fairing is compared with the original spectrum to show the effect of the combination of the two corrections (atmospheric absorption and ground reflection). Also shown is the original SPL spectrum corrected by removing the atmospheric absorption. The $\mathrm{SPL}_{\mathrm{m}}$ corrected for atmospheric absorption for these data is shown to be about $1 \mathrm{~dB}$ above the lossless spectrum from 5000 hertz to 10,000 hertz in accordance with correction for the ground 
reflection. The atmospheric attenuation loss above 10,000 hertz causes the measured data, $\mathrm{SPL}_{\mathrm{m}}$, to be lower than the free field $\mathrm{SPL}^{+}$curve.

Hereinafter, for simplicity the results of the computer method (i.e. the computer corrected $\mathrm{SPL}_{\mathrm{m}}^{+}$spectra and the equation calculated $\mathrm{SPL}_{\mathrm{Cal}}^{+}$) will be shown rather than smooth $\mathrm{SPL}^{+}$curves produced by fairing to the $\mathrm{SPL}_{\mathrm{m}}^{+}$or $\mathrm{SPL}_{\mathrm{cal}}^{+}$curves.

Results for Various Microphone Heights

Measured spectra. - Typical sound pressure level spectra for the $33.02 \mathrm{~cm}(13-i n c h)$ diameter nozzle taken at various microphone heights at distances of $7.62,15.24$, and $22.86 \mathrm{~m}(25,50$, and $75 \mathrm{ft})$ from the nozzle exit are shown in figure 4. Cancellations and reinforcement effects due to ground reflections are seen to be quite pronounced for frequencies below around $1500 \mathrm{~Hz}$. The data also show the wide range of pressure level values that can be obtained in this frequency range due to variation in microphone height. The data presented are for a nozzle exhaust velocity of $301 \mathrm{~m} / \mathrm{sec}$ (988 ft/sec). Similar trends were observed at other velocities.

Lossless spectra. - Lossless SPL spectra were calculated based on correcting the measured values (SPL ${ }_{\mathrm{m}}^{+}$, eq. (12)) for the data of figure 4 for the same exhaust velocity and microphone heights and distances. For the data taken with microphones on the ground, two different procedures were used to correct the ground microphone data for reflection effects: the first was to subtract $6 \mathrm{~dB}$; and the second was to subtract a reflectance, $|\mathrm{T}|^{2}$, found by the computer method. The results for the $\mathrm{SPL}_{\mathrm{m}}^{+} \mathrm{spec-}$ tra are shown in figure 5. 
A value for each measurement of the magnitude of the reflected signal transfer function $Q$ and its phase $\delta$ was found with the computer method described herein. The values of $Q$ are listed for each calculated spectra in figure 5. The resulting range in values of $Q$ could be attributed to non-uniformity in the asphalt absorption and/or atmospheric effects on sound propagation. The variation of $Q$ is discussed in Appendix $C$.

The results shown in figure 5 indicate that, in comparison with figure 4 , the scatter in the data has been greatly reduced in the region where ground effects were pronounced. At the various distances from the nozzle data at each of the microphone heights (continuous 1ines) are in relatively good agreement and indicate the relative effectiveness of the correction calculation.

Examination of detailed variations. - Figure $5(\mathrm{a})$ shows that the $\mathrm{SPL}_{\mathrm{m}}^{+}$ spectra for microphones $7.62 \mathrm{~m}(25 \mathrm{ft})$ from the nozzle and heights of 0.30 , $.91,1.52$, and $3.89 \mathrm{~m}(1,3,5$, and $123 / 4 \mathrm{ft})$ are in good agreement over the entire frequency range. The $7.62 \mathrm{~m}$ (25 ft) radius ground microphone $\mathrm{SPL}_{\mathrm{m}}^{+}$spectra corrected using a value of $\mathrm{Q}=0.91$ for the magnitude of the reflected ray $\left(|\mathrm{T}|^{2} \simeq 5 \mathrm{~dB}\right)$ is consistent with the $\operatorname{SPL}_{\mathrm{m}}^{+}$data at 0.30 , $0.91,1.52$, and $3.89 \mathrm{~m}(1,3,5$, and $123 / 4 \mathrm{ft})$ up to 1600 hertz. No explanation is avallable, at present, as to why there is no agreement above 1600 hertz.

Figure 5(b) shows that the $\mathrm{SPL}_{\mathrm{m}}^{+}$spectra for microphones $15.24 \mathrm{~m}$ (50 ft) from the nozzle and at heights of $0.91,1,52$, and $3.89 \mathrm{~m}(3,5$, and $123 / 4 \mathrm{ft})$ are again in good agreement. However, above 5000 hertz the $\mathrm{SPL}_{\mathrm{m}}^{+}$spectra for 
$0.91(3 \mathrm{ft})$ is higher than the 1.52 and $3.89 \mathrm{~m} \mathrm{(5} \mathrm{and} 123 / 4 \mathrm{ft}$ ) data. The 15.24 (50 ft) ground microphone $\mathrm{SPL}_{\mathrm{m}}^{+}$data shown in figure $5(\mathrm{~b})$ corrected by subtracting $6 \mathrm{~dB}$ are in agreement with the $\mathrm{SPL}_{\mathrm{m}}^{+}$data taken at $0.91,1.52$, and $3.89 \mathrm{~m}(3,5$, and $123 / 4 \mathrm{ft}$ ) only up to 500 hertz. At higher frequencies than 500 hertz, subtracting $6 \mathrm{~dB}$ appears to produce too large a correction. The ground microphone data corrected using $Q=$ $0.637\left(|\mathrm{~T}|^{2} \simeq 4.3 \mathrm{~dB}\right)$ appears to be undercorrecting the ground microphone spectra below 500 hertz; however, above 500 hertz the use of the calculated correction causes the ground microphone data to be in agreement with the $\mathrm{SPL}_{\mathrm{Tm}}^{+}$spectra for microphones at $0.91,1.52$, and $3.89 \mathrm{~m}(3,5$, and $123 / 4 \mathrm{ft})$. Figure 5(c) shows that the $\mathrm{SPL}_{\mathrm{m}}^{+}$spectra for microphones $22.86 \mathrm{~m}$ (75 $\mathrm{ft}$ ) from the nozzle and heights of $0.91,1.52$, and $3.89 \mathrm{~m}(3,5$, and $123 / 4 \mathrm{ft})$ are in very good agreement over the entire frequency range. The ground microphone $\mathrm{SPL}_{\mathrm{m}}^{+}$data corrected using $Q=0.637\left(|\mathrm{~T}|^{2} \simeq 4.3 \mathrm{~dB}\right)$ is in good agreement with the data up to 10,000 hertz. However, the $22.86 \mathrm{~m}$ (75 ft) ground microphone $\mathrm{SPL}_{\mathrm{m}}^{+}$data shown in figure $5(\mathrm{c})$ corrected by subtracting $6 \mathrm{~dB}$ appears to be overcorrected.

Individual comparisons. - Comparisons of the measured sound pressure level and the lossless sound pressure level calculated by applying the corrections found by the computer method at each of the four heights are shown In figure 6. The reduction of the magnitude of the effect of the reinforcements and cancellations due to ground reflection in each case is seen more clearly in the figure.

As indicated previously, the method also provides a least square curve fit to the SPL ${ }_{m}^{+}$level spectra. Figure 7 shows comparisons between SPL $L_{m}^{+}$and 
$\mathrm{SPL}_{\mathrm{cal}}^{+}$for two cases. Faired curves for the $\mathrm{SPL}_{\mathrm{m}}^{+}$and the SPL $\mathrm{Sal}_{\mathrm{c}}^{+}$variations at each microphone height can then be used to provide a reasonably accurate determination of the "true" lossless spectrum for each test condition.

Selective Placement of

Reinforcements and Cancellations

As an alternative to the computer method to correct ground reflection effects, use can be made of selective placement of reinforcements and cancellations. This can be achieved most simply by changing the microphone height. For a given rig geometry having a specific source height and at a given radius, moving the microphone close to the ground moves the location of the first cancellation to higher frequencies, while moving the microphone far from the ground moves the location of the first cancellation to lower frequencies. Calculations to select the most desirable microphones heights can be made using the equations presented herein to simulate measured SPL spectra for different test geometries.

Another way to correct ground reflection effects is to combine nearor on-the-ground microphone spectra with high-above-the-ground microphone spectra. However, while the reflectance for measurements made by near- or on-the-ground microphone is constant over a large frequency range (eq. (13)), the value of the constant level still depends on the magnitude of the reflected signal transfer function, Q. Also, while a microphone high above the ground produces a measured spectrum level which has its first cancellation at low frequencies, the average reflectance at high frequencies still 
depends on the magnitude of the reflected signal transfer function. Hence while near- or on-the-ground microphone spectra can be combined with highabove-the-ground microphone spectra to obtain data free of cancellations and reinforcements, the effect of ground reflections may still be present. Some estimate of the value of $Q$ should be made and the proper correction should be applied to both ground microphone and high-above-the-ground microphone spectra data before they are combined. The computer method discussed herein can be used to obtain the necessary value of $Q$.

From the data presented herein, it is speculated that if the lossless SPL spectra accuracy needs to be only $\pm 2 \mathrm{~dB}$, it would be sufficient to assume the reflectance for a microphone near or on the ground can be expressed by

$$
|\mathrm{T}|^{2}=10 \log _{10}(1+1 / z)^{2}-1
$$

and the reflectance for a microphone high above the ground can be expressed by

$$
|T|^{2}=10 \log _{10}(1+1 / 2)^{2}-1
$$

These assumptions could be checked using the method described herein.

In general the frequencies of the cancellations and reinforcements are fixed by the facility geometry. The magnitude of the problem caused by reflection effects in any test will depend on the frequency range of interest of the scale model being tested. For studies where the frequency range of interest is above the location of the cancellations and reinforce- 
ments and where only relative level changes are important, the ground reflection effects may not be pertinent,

\section{CONCLUDING REMARKS}

This study has shown that the effects of ground reflections on jet notse spectra can be satisfactorily corrected by a computer method. The computer method was based on an analysis of ground reflection effects using the concept of a reflected signal transfer function which represents the effects of both the reflecting surface and the atmosphere on the propagation of the reflected signal in a mathematical model. The computer method, besides being useful in correcting measured data, can be employed to predict the results of using a particular microphone array or test site treatment.

Ground effects can also be avoided or minimized by appropriate placement of the microphone array to produce selective placement of reinforcements and cancellations. The computer method can also be helpful in this approach. 


\section{APPENDIX A}

\section{SYMBOLS}

A

$\mathrm{C}_{\mathrm{e}}$

$\mathrm{c}_{0}$

$C_{\text {pen }}$

$\mathrm{C}_{\mathrm{R}}$

$\mathrm{C}_{\mathrm{T}}$

$c_{1}, c_{2}, c_{3}$

$c_{0}$

$c_{2}$

$\mathrm{D}_{\mathrm{e}}$

E

f

$f_{c}$

$G(s)$

ho

$h_{s}(n)$

j

Ma

N

$\mathrm{N}_{\mathrm{b}}$

n

atmospheric attenuation level, dB

cost function, sum of square of error between measured

and calculated sound spectra

$\mathrm{PSD}^{+}$function level at zero Strouhal number, (eq. (B-3)), dB

penalty function

reflection coefficient

total cost function

cancellation frequencies, $\mathrm{Hz}$

velocity of sound in air, $\mathrm{m} / \mathrm{sec}$

velocity of sound in surface, $\mathrm{m} / \mathrm{sec}$

effective diameter, m

Strouhal response function, (eq. (B-4))

frequency, $\mathrm{Hz}$

nominal one-third-octave band frequency, $\mathrm{Hz}$

reflected signal transfer function

microphone height, m

height of $n^{\text {th }}$ source, $m$

$\sqrt{-1}$

number of $E$ terms summed to form $\mathrm{PSD}^{+}$

number of independent noise sources

number of $E$ terms subtracted to form $\mathrm{PSD}^{+}$

source index 
OASPL

OASPL $_{p}^{+}$

PSD

PSD $^{+}$

$\mathrm{PSD}_{\mathrm{ca1}}^{+}$

$\mathrm{pr}_{\mathrm{r}}$

$Q(s)$

$R_{2}, R_{3}, R_{4}$

I

SPL

$\mathrm{SPL}^{+}$

SPL $L_{\text {cal }}$

SPL $_{\text {caI }}^{+}$

$\mathrm{SPL}_{\mathrm{Tn}}$

$\mathrm{SPL}_{\mathrm{m}}^{+}$

St

$S t_{p}$

$s$

$s_{1}$ overall sound pressure level relative to $\mathrm{p}_{\mathrm{r}}$, $\mathrm{dB}$

lossless OASPL parametric value, $\mathrm{dB}$

normalized mean-square pressure spectral density level, dB

PSD without atmospheric absorption and ground reflection

effects, $d B$

$\mathrm{PSD}^{+}$calculated by an equation for a real random process spectrum density, $d B$

reference pressure $2 \times 10^{-5}$ Pascal ( $2 \times 10^{-4}$ microbar)

magnitude of reflected signal transfer function

reinforcement frequency

distance from source to microphone

one-third-octave sound pressure level referenced to $\mathrm{Pr}_{r}, \mathrm{~dB}$

SPL that would be measured without atmospheric attenuation and in the absence of a reflecting surface (lossless SPL), $d B$

SPL calculated from equation (16), dB

lossless SPL calculated from equation (B-1), $d B$

SPL measured, dB

lossless SPL calculated from data by equation (12), dB

Strouhal number, $f\left(D_{e} / V_{e}\right)$

critical Strouhal number

$j 2 \pi f, j \omega$

distance from source to microphone along direct signal path, $m$ 


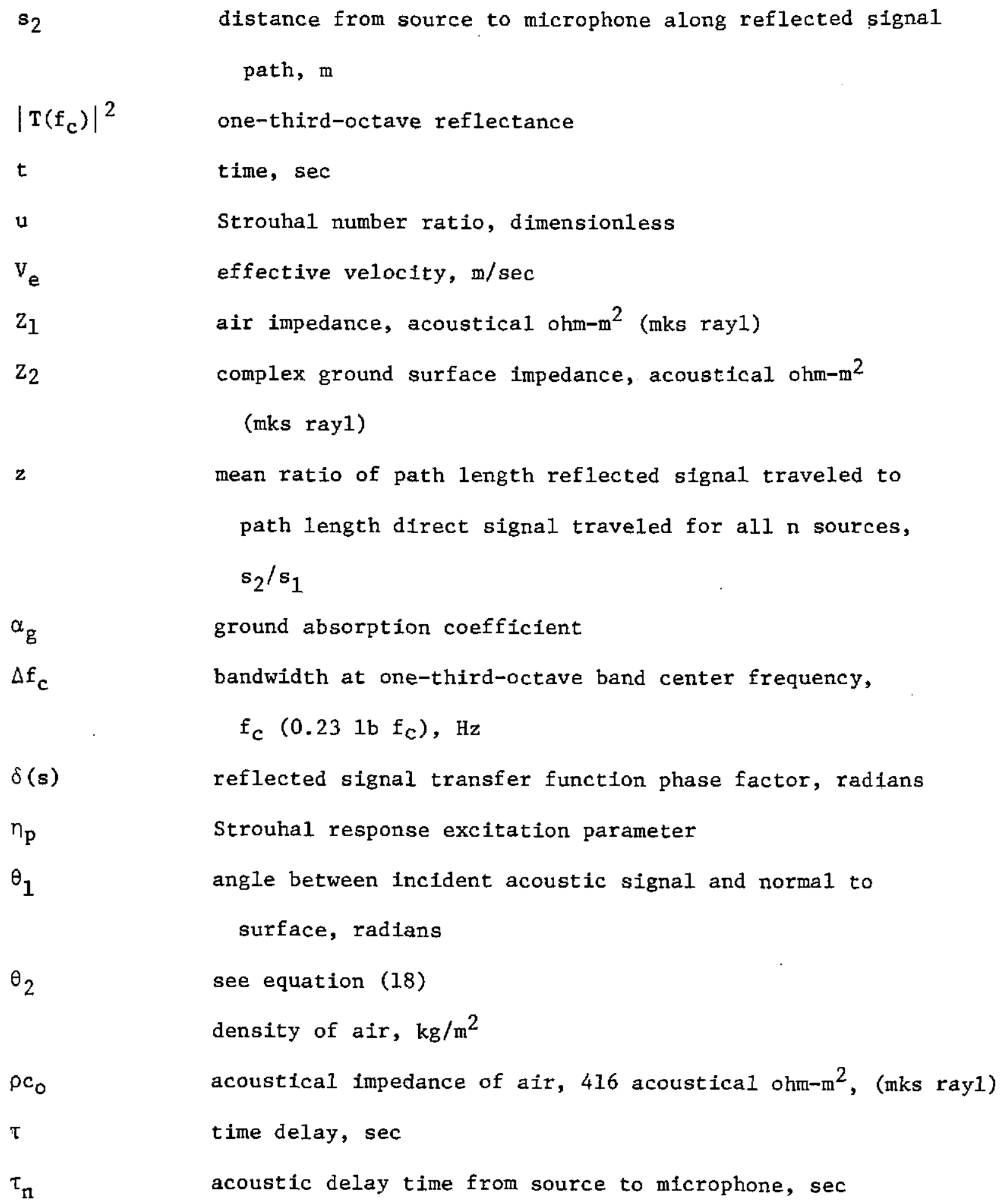


$\omega$

Subscripts:

ca1

$i$

$\mathbf{k}$

m

o

p

pen

R

$r$

s

$\mathrm{T}$

Superscripts

$+$ angular velocity; $2 \pi f$, rad/sec

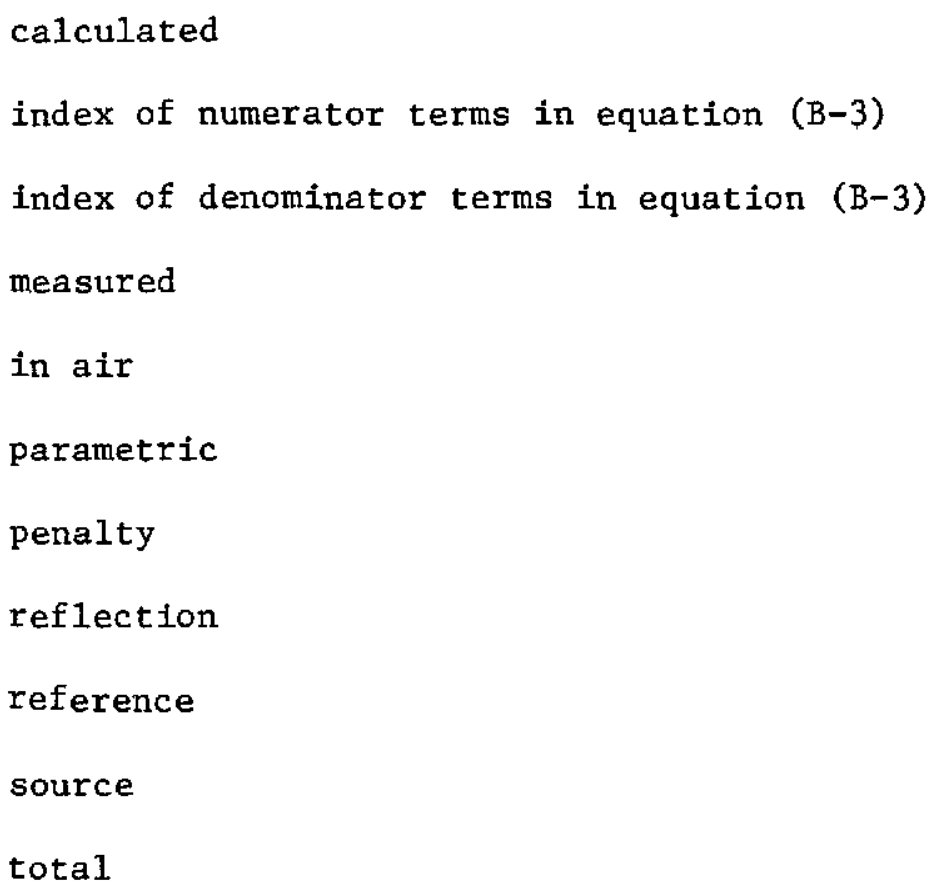

evaluated with reflection and atmospheric attenuation effects removed 
APPENDIX B

ANALYTICAL LOSSLESS SPL SPECTRA

The lossless third octave SPL spectra equation used herein is

$$
\mathrm{SPL}_{\mathrm{cal}}^{+}(\ell)=10 \log _{10} \quad 10^{\mathrm{OASPL}_{\mathrm{p}}^{+} / 10} \quad \Delta \mathrm{f}_{\mathrm{c}} \frac{\mathrm{D}_{\mathrm{e}}}{\mathrm{V}_{\mathrm{e}}}+\mathrm{PSD}_{\mathrm{cal}}^{+}
$$

where

$$
\operatorname{OASPL}_{\mathrm{p}}^{+}=10 \log _{10} \sum_{\ell} 10 \frac{\mathrm{SPL}^{+}(\ell)}{10_{\mathrm{ca} 1}}
$$

(Al1 symbols are defined in the symbol 1ist.) The quantity denoted as $\mathrm{PSD}_{\mathrm{cal}}^{+}$is the normalized mean square pressure spectral density level.

The following semi-empirical formula presented in Appendix $E$ of reference 3 is used herein to represent the $\mathrm{PSD}_{\text {cal }}^{+}$function.

$$
\operatorname{PSD}_{\mathrm{cal}}^{+}=\mathrm{C}_{\mathrm{o}}+\sum_{i=1}^{\mathrm{M}_{\mathrm{a}}} \mathrm{E}\left[\mathrm{u}(\mathrm{i}), \eta_{\mathrm{p}}(\mathrm{i})\right]-\sum_{\mathrm{k}=1}^{\mathrm{N}_{\mathrm{b}}} \mathrm{E}\left[\mathrm{u}(\mathrm{k}), \eta_{\mathrm{p}}(\mathrm{k})\right]
$$

where $\mathrm{E}$ is the Strouhal response function which represents a real random process spectral density

$$
E\left(u, \eta_{p}\right)=10 \log _{10}\left\{\left[\frac{\eta_{p}^{2}+(u-1)^{2}}{\eta_{p}^{2}+1}\right]\left[\frac{\eta_{p}^{2}+(u+1)}{\eta_{p}^{2}+u^{2}+1}\right]\right\}
$$


u is the Strouhal number ratio

$$
u=S t / S t_{p}
$$

$p$ is the Strouhal response excitation parameter, and $S t_{p}$ is the critical Strouhal number. The normalization constant, $\mathrm{C}_{\mathrm{o}}$ from equation $(B-1)$ and $(B-2)$ is adjusted so that

$$
\sum_{\ell} \frac{\Delta \mathrm{f}_{c}(l)}{V_{\mathrm{e}}} \mathrm{D}_{\mathrm{e}}{ }_{10} \operatorname{PSD}_{\mathrm{cal}}^{+}(\ell) / 10=1
$$




\author{
APPENDIX C \\ THE REFLECTED SIGNAL TRANSFER FUNCTION
}

The relatively large range of values of the magnitude of the reflected signal transfer function, $Q$, used in analyzing the data shown in figure 5 can be explained by two different interpretations of the reflected signal transfer function $\left(G\left(f_{c}\right)=Q_{e}{ }^{j \delta}\right)$. Briefly, the reflected signal transfer function can be considered as providing information about the reflecting surface and/or as providing information about the propagation of the reflected signal. The results will be interpreted in terms of these two factors.

Propagation processes. - In terms of the propagation process, the value of the magnitude of $Q$ indicates the amount of correlation between the direct and reflected signal. If the direct and reflected signals were not correlated, the measured spectrum would represent the sum of the squares of the direct and reflected signals and no cancellations or reinforcements would occur.

The occurrence of a small cancellation and reinforcement effect makes interpretation of the $\mathrm{SPL}_{\mathrm{m}}$ data difficult. As an example, the data taken at a $7.62 \mathrm{~m}(25 \mathrm{ft}$ ) radius for microphone heights of 1.52 and $3.89 \mathrm{~m}$ (5 and $123 / 4 \mathrm{ft}$ ) above the asphalt surface (shown in fig. 4(a)) was duplicated by the computer procedure using a $Q$ value of 0.3 (fig. 5(a)). This value of $Q$ indicates the presence of cancellations and reinforcements of reduced magnitude. However, the data taken at $7.62 \mathrm{~m}(25 \mathrm{ft})$ radius for microphone 
heights of 0.30 and $.91 \mathrm{~m}$ ( 1 and $3 \mathrm{ft}$ ) above the asphalt surface (shown in fig. 4(a)) was duplicated using $Q$ values of 0.5 and 0.614 . Since the asphalt surface was the same in both cases, this indicates that the correlation between the direct and reflected signals could have been modified by other propagation processes than ground reflection effects. Some propagation processes which might be a factor are scattering, turbulence in the atmosphere and fluctuations of wing and temperature gradients with time. Investigation of these factors is beyond the scope of this report. Surface impedance. - If it is assumed that the direct and reflected signal correlation are unaffected by atmospheric effects, then the asphalt surface impedance can be a factor. The computer in correcting the data calculates the reflected signal transfer function, $G=Q_{e}{ }^{i \delta}$. Figure 8 shows a typical plot of the complex number $G$ for a given microphone distance. For all of the distances covered, the magnitude of $G$ ranged from 0.3 to 0.8 and the average value was near 0.6 .

From equation (7) the ratio of the impedance of the asphalt to that of air is

$$
\frac{Z_{2}}{Z_{1}}=\left(\frac{1+Q_{e}{ }^{1 \delta}}{1+Q_{e}^{i \delta}}\right) \frac{\cos \theta_{2}}{\cos \theta_{1}}
$$

Using the values shown in figure 8 for $G$ and letting $\cos \theta_{2}=1$ the value of $\left(z_{2} / z_{1}\right)$ was found. Typical values of $z_{2} / z_{1}$ are plotted in figure 9. For all the cases studied the magnitude of $z_{2} / z_{1}$ ranged from 10 to 25 for microphones at 15.24 and $22.66 \mathrm{~m}(50$ and $75 \mathrm{ft}$ ) and the average value was about 17 . 
Reflectance. - Figure 10 shows the reflectance calculated using the assumption $Q=1$ (perfect reflection) and using the computer selected value of $Q$. Comparison indicates that the cancellations and reinforcements are larger when $Q=1$. The value of $Q$ selected by the computer decreases the magnitude of the cancellations and reinforcements and also introduces a phase shift. From equation (3), the first cancellation occurs when

$$
\cos \left(2 \pi f \tau_{n}-\delta\right)=-1
$$

or for $\delta=0$, at

$$
\mathrm{f}_{\mathrm{c}}=\frac{1}{2 \tau_{\mathrm{n}}}=\frac{\mathrm{c}_{o}}{2\left(\mathrm{~s}_{2}-\mathrm{s}_{1}\right)}
$$

When $\delta$ is near zero, the first cancellation occurs at

$$
f_{c}=\frac{\delta_{+} \pi}{2 \pi} \frac{c_{o}}{\left(s_{2} s_{1}\right)}
$$

Thus the computer as shown in figure 10 selected small positive values of $\delta$ for microphone heights of 0.91 and $3.89 \mathrm{~m}$ ( 3 and $123 / 4 \mathrm{ft}$ ). This resulted in the shift of the first reinforcement about one third octave band higher than when $\delta$ was zero. This phase shift may be due to the impedance of the asphalt or to changes in path length from temperature or wind gradients. Thus the impedances shown in figure 9 are probably in error. 


\section{REFERENCES}

1. Howes, Walton L.: Ground Reflection of Jet Noise. NASA TR R-35, 1959.

2. Miles, J. H.: Rational Function Representation of Flap Noise Spectra Including Correction for Reflection Effects. Paper No. 74-193, AIAA, Jan.-Feb. 1974 .

3. Miles, J.H.: Method of Representation of Acoustic Spectra and Reflection Corrections Applied to Externally Blown Flap Noise. NASA TM X-3179, 1975.

4. Thomas, P.: Acoustic Interference by Reflection: Application to the Sound Pressure Spectrum of Jets. AGARD Aircraft Engine Noise and Sonic Boom. AGARD-CP-24, 1969.

5. Anon: Standard Values of Atmospheric Absorption as a Function of Temperature and Humidty for Use in Evaluating Aircraft Flyover Noise. Aerospace Recommended Practice No. 866, SAE, Aug. 1964.

6. Evans, L. B.; and Sutherland, L. C.: Absorption of Sound in Air. WR 70-14, Wyle Labs. (AD-710291; AROD-8725-2-E), 1970.

7. Rayleigh, J. W. S.: The Theory of Sound. Volume II. P. 78, Dover Publications, Inc., 1948. Unabridged republication of the second revised and enlarged edition of 1896 originally published by the MacMillan Company.

8. Morse, Phillip M.; and Ingard, K. U.: Theoretical Acoustics. McGraw-Hill Book Co., Inc., 1968. 
9. Wise, W. H.: Asymptotic Dipole Radiation Formulas. Bell Sys. Tech. Journal, vo1. 8, October 1929, pp. 662-671.

10. Delany, M. E.; and Bazley, E. N.: A Note on the Effect of Ground Absorption in the Measurement of Aircraft Noise. J. Sound Vib., vo1. 16, no. 3, June 1971, pp. 315-322.

11. Rudnick, Isadore: The Propagation of an Acoustic Wave Along a Boundary. J. Acous. Soc。Am。, vol. 19 (2), March 1947, pp. 348-356.

12. Norton, K. A.: The Propagation of Radio Waves Over the Surface of the Earth and in the Upper Atmosphere. Proceedings of the Institute of Radio Engineers, vol. 24 (10), October 1936, pp. 1367-1387, part I; vo1. 25 (9), September 1937, pp. 1203-1236, part II.

13. Dickinson, P. J.; and Doak, P. E.: Measurements of the Normal Acoustic Impedance of Ground Surfaces. J. Sound Vib., vol. 13, no. 3, Nov. 1970, pp. 309-322.

14. Aoki, Masano: Introduction to Optimization Techniques. The MacMjllan Company, 1971.

15. Pierre, Donald A.: Optimization Theory with Applications. John Wiley \& Sons, Inc., 1969.

16. Powel1, M. J. D.: An Efficient Method for Finding the Minimum of a Function of Several Variables Without Calculating Derivatives. Computer Journa1, vol. 7, no. 2, Ju1y 1964, pp. 155-162.

17. Shapiro, Miriam S.; and Goldstein, Max: A Collection of Mathematical Computer Routines. NYo-1480-14, New York University, 1965.

18. Miles, Jeffrey H.: Computer Method for Identification of Boiler Transfer Functions. NASA TM X-2436, 1971. 
19. Goodykoontz, Jack H.; Dorsch, Robert G.; and Groesbeck, Donald, E.: Noise Tests of a Mixer Nozzle Externally Blown Flap System. NASA TN D-7236, 1973. 
TABLE I. - MICROPHONE LOCATIONS

\begin{tabular}{lll}
$\begin{array}{c}\text { Microphone } \\
\text { Angle, } \\
\text { Degrees, }\end{array}$ & $\begin{array}{c}\text { Microphone } \\
\text { Radius, }\end{array}$ & \multicolumn{1}{c}{$\begin{array}{c}\text { Microphone } \\
\text { Height, } \\
\mathrm{h}_{\mathrm{O}}\end{array}$} \\
\cline { 2 - 3 } & $\mathrm{ft}$ & $\mathrm{mt}$ \\
\hline
\end{tabular}

$7.62 \mathrm{~m}(25 \mathrm{ft})$ from nozzle exit

\begin{tabular}{rllll}
\hline 160 & 6.55 & 21.51 & 0.0061 & 0.02 \\
155 & 6.71 & 22 & 0.3048 & 1 \\
150 & 7.01 & 23 & 0.9144 & 3 \\
145 & 7.32 & 24 & 1.5240 & 5 \\
145 & 7.62 & 25 & 3.89 & 12.75 \\
\hline
\end{tabular}

$15.24 \mathrm{~m}$ (50 ft) from nozzle exit

\begin{tabular}{|c|c|c|c|c|}
\hline $\begin{array}{l}150 \\
150 \\
145 \\
145 \\
145 \\
\end{array}$ & $\begin{array}{l}14.63 \\
14.63 \\
15.24 \\
15.24 \\
15.24 \\
\end{array}$ & $\begin{array}{l}48 \\
48 \\
50 \\
50 \\
50 \\
\end{array}$ & $\begin{array}{l}0.0061 \\
0.3048 \\
0.9144 \\
1.5240 \\
3.89 \\
\end{array}$ & $\begin{array}{l}0.02 \\
1 \\
3 \\
5 \\
12.75 \\
\end{array}$ \\
\hline \multicolumn{5}{|c|}{$22.86 \mathrm{~m}(75 \mathrm{ft})$ from nozzle exit } \\
\hline $\begin{array}{l}145 \\
145 \\
145 \\
145 \\
\end{array}$ & $\begin{array}{l}22.86 \\
22.86 \\
22.86 \\
22.86 \\
\end{array}$ & $\begin{array}{l}75 \\
75 \\
75 \\
75 \\
\end{array}$ & $\begin{array}{l}0.0061 \\
0.9144 \\
1.5240 \\
3.89\end{array}$ & $\begin{array}{r}0.02 \\
3 \\
5 \\
12.75 \\
\end{array}$ \\
\hline \multicolumn{5}{|c|}{$7.62 \mathrm{~m}(25 \mathrm{ft})$ from nozzle exit } \\
\hline $\begin{array}{l}125 \\
100 \\
\end{array}$ & $\begin{array}{l}7.62 \\
7.62 \\
\end{array}$ & $\begin{array}{l}25 \\
25 \\
\end{array}$ & $\begin{array}{r}3.89 \\
3.89 \\
\end{array}$ & $\begin{array}{l}12.75 \\
12.75 \\
\end{array}$ \\
\hline
\end{tabular}




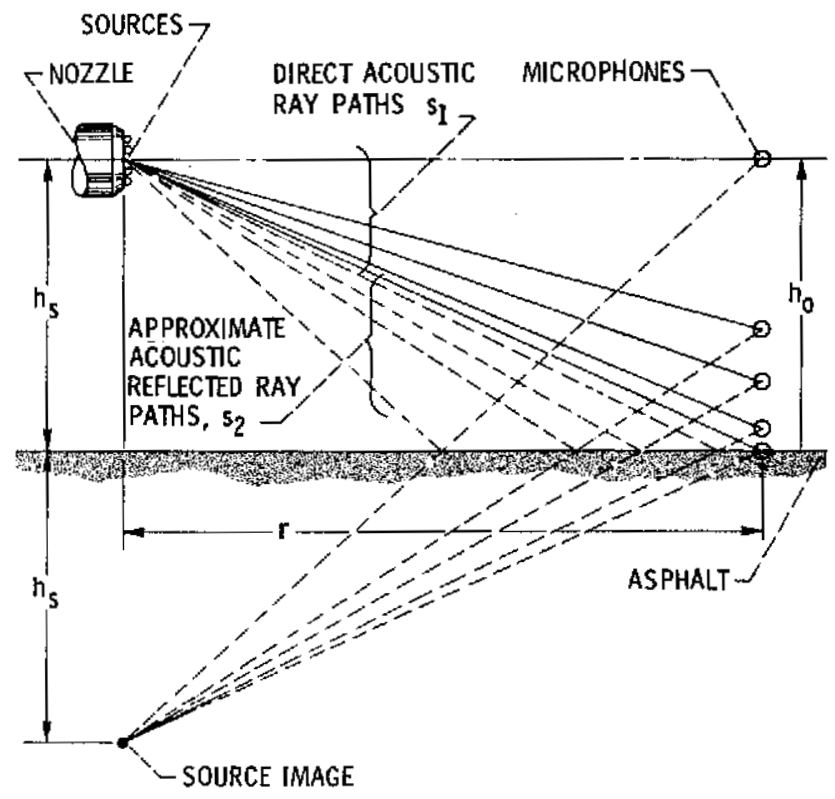

Figure 1. - Schematic of nozzle and microphone geometry relative to asphalt surface.

\section{ORIGINAL PAGE IS} OF POOR QUALITY 


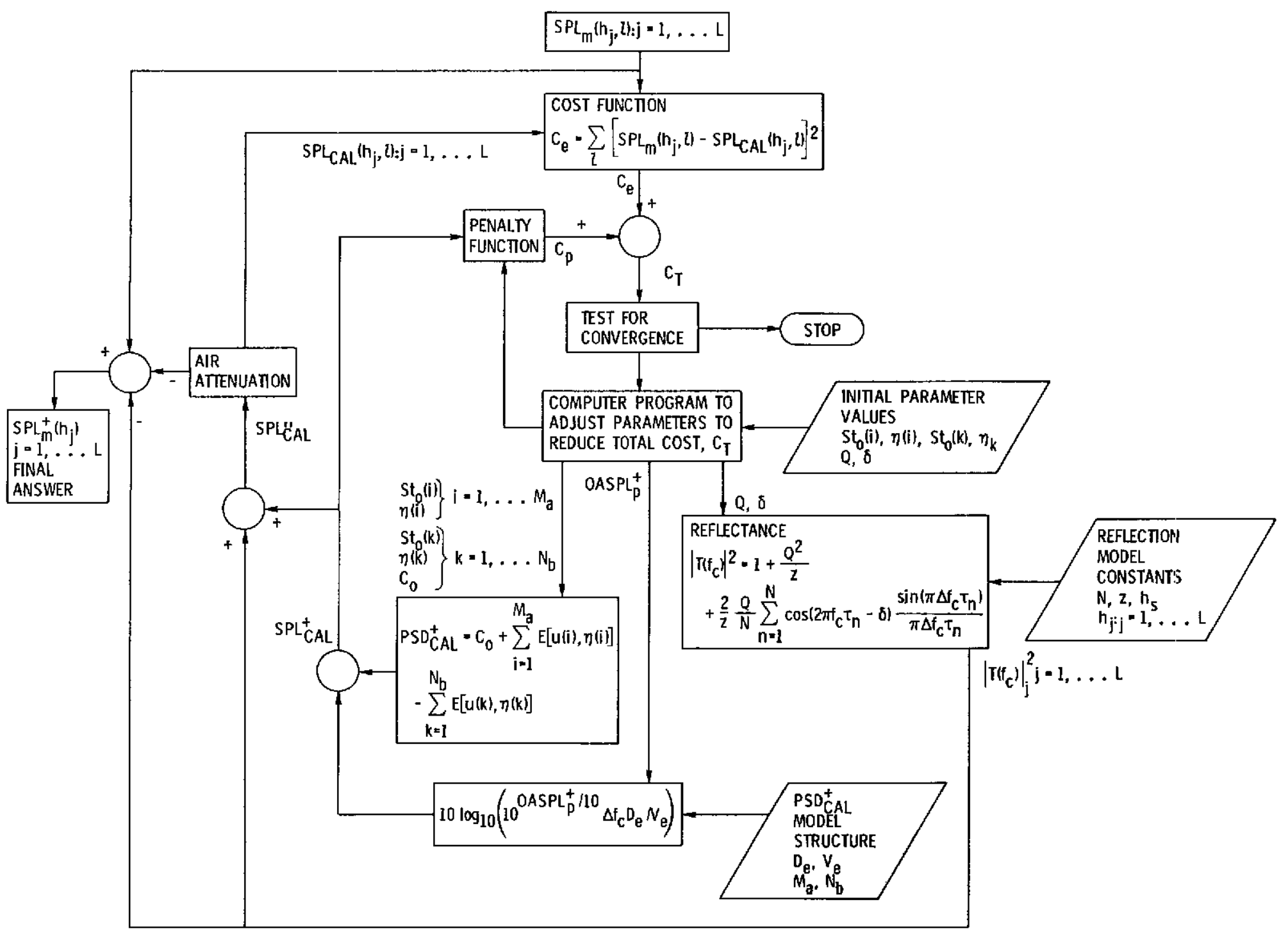

Figure 2 - Diagram of computer method. 


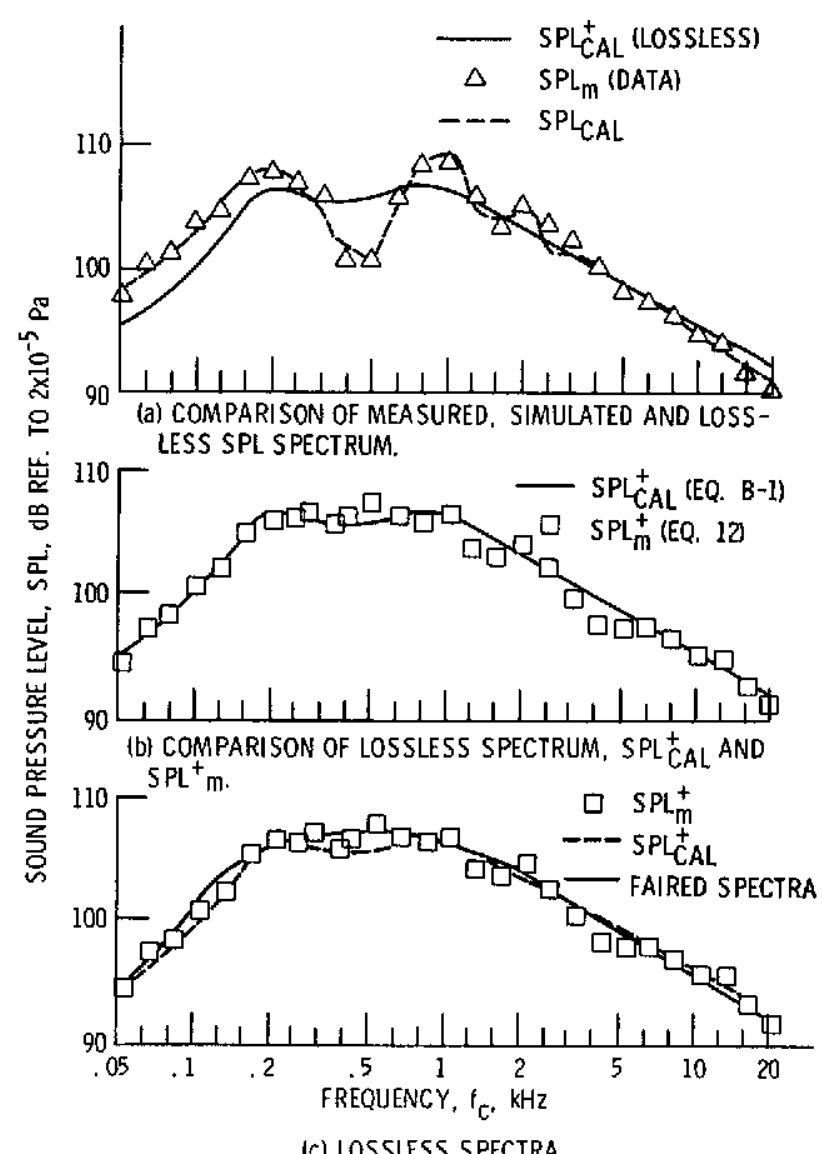

Figure 3. - Example of measured and computer-calculated spectral results. Microphone height, $0.3048 \mathrm{~m}_{\text {i }}$ source height, $3.89 \mathrm{~m}$; radius, $7.62 \mathrm{~m}$. Nozzle exhaust vel $\propto$ ity $301 \mathrm{~m} / \mathrm{sec}$; directivity angle, $145^{\circ}: Q=0.605$. $\delta=6.36$.

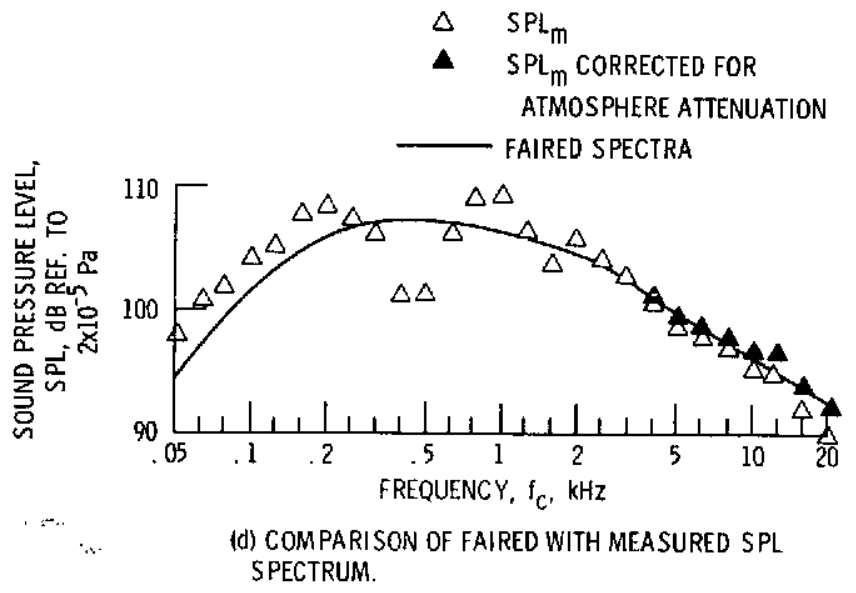

Figure 3. - Concluded. 


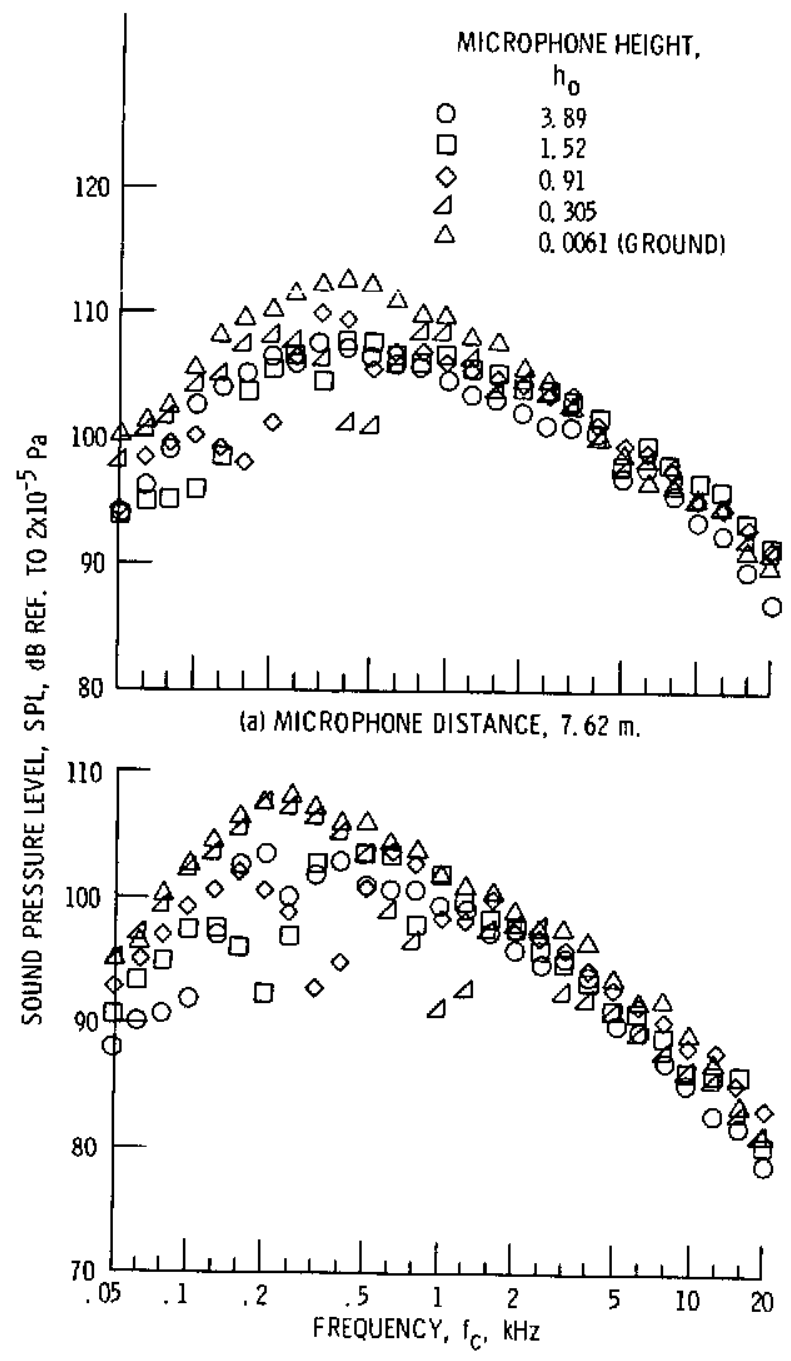

(b) MICROPHONE DISTANCE, $15.24 \mathrm{~m}$.

Figure 4, - Effect of microphone height on measured spectrum for various microphone radial distances. Directivity angle, $145^{\circ}$.

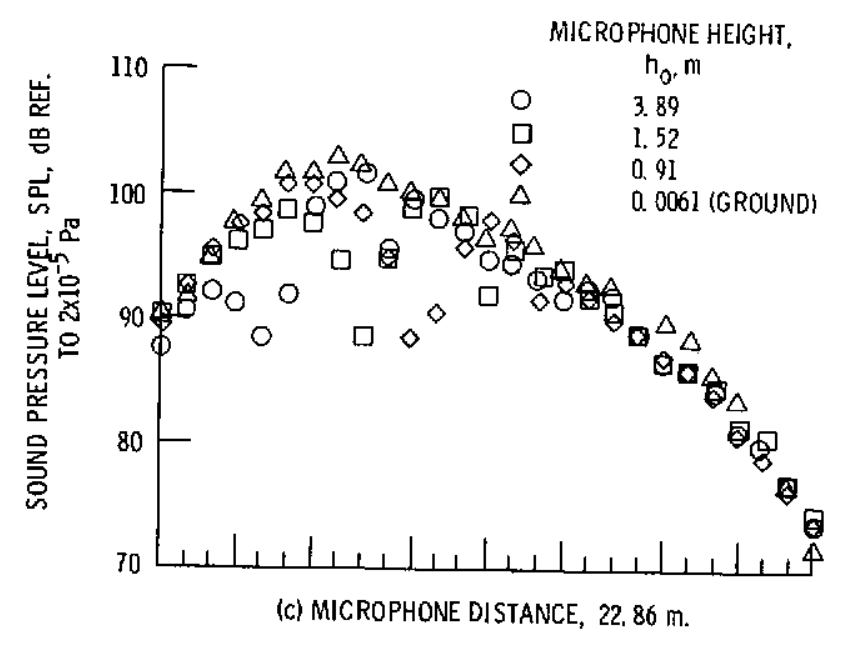

Figure 4. - Concluded. 


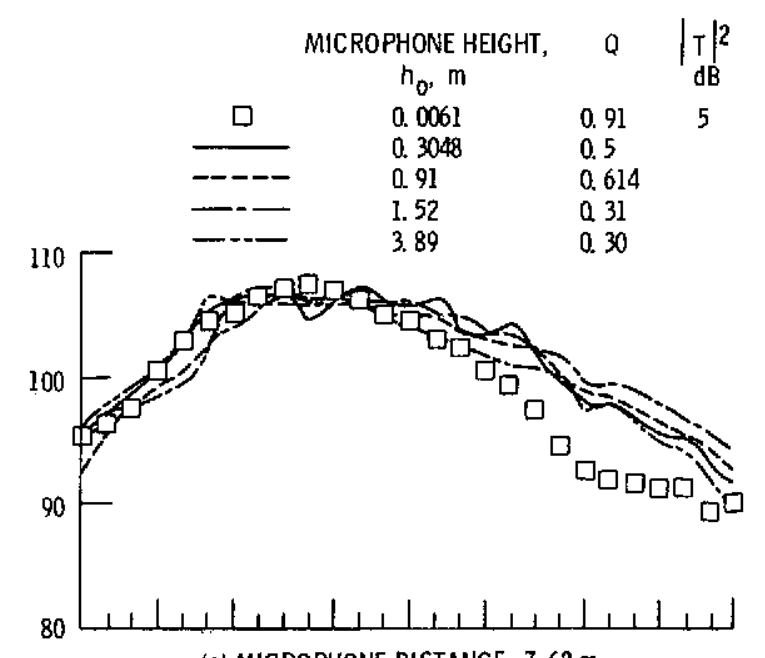

(a) MICROPHONE DISTANCE, $7.62 \mathrm{~m}$.
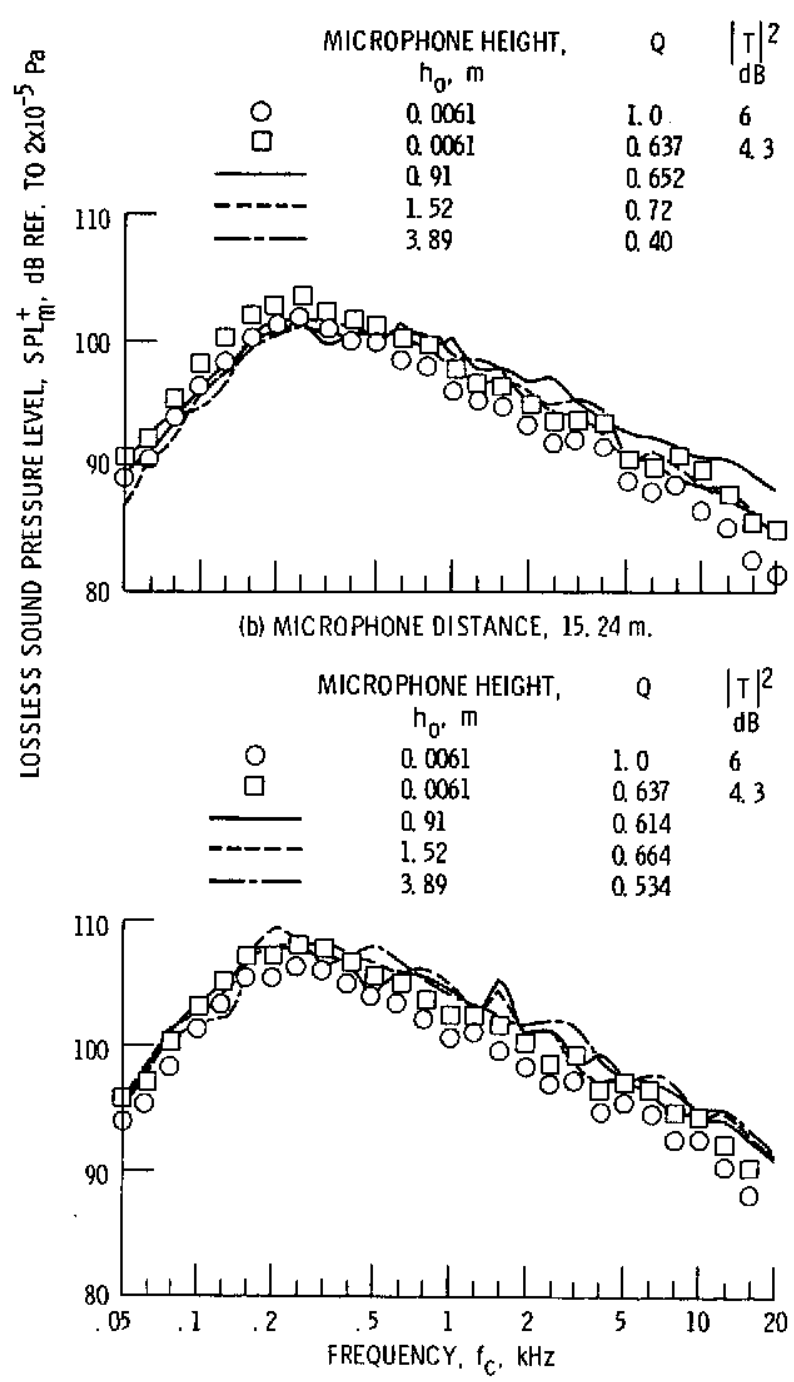

(c) MICROPHONE DISTANCE, $22.86 \mathrm{~m}$.

Figure 5. - Comparison of lossless sound pressure level spectra based on corrected measured data taken at ground level and at various microphone heights for several microphone radial distances. 


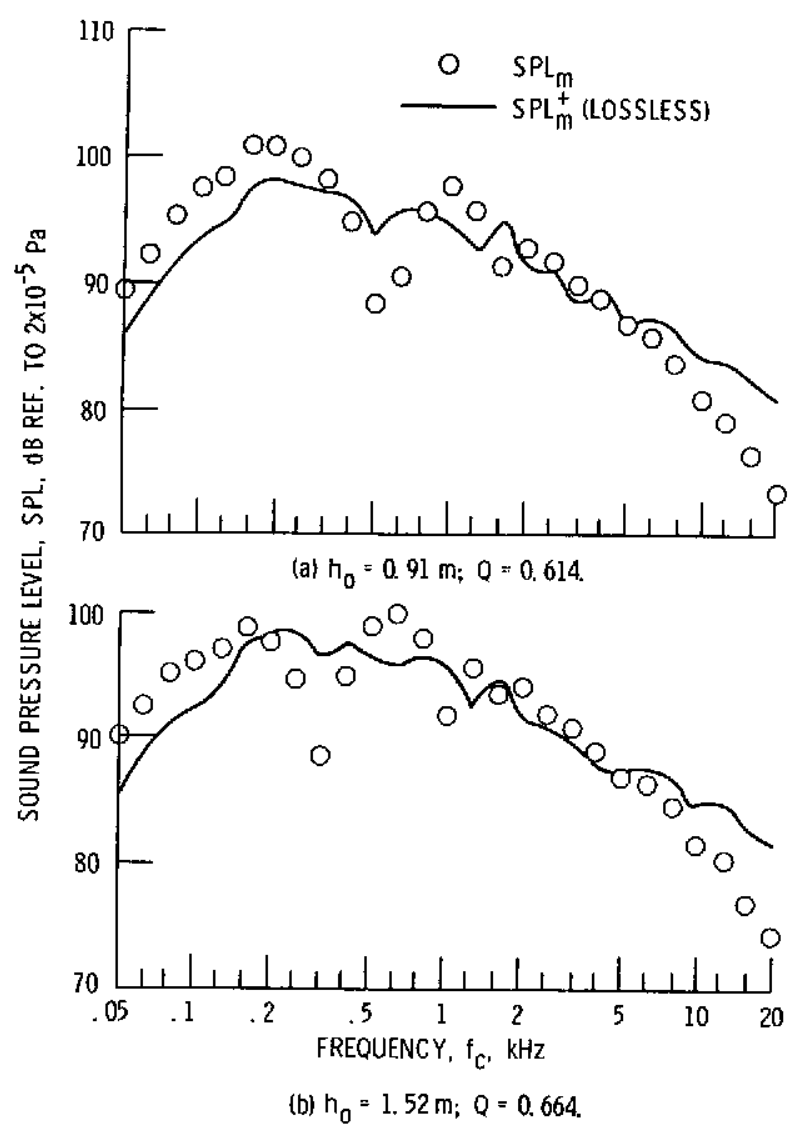

Figure 6. - Comparison of measured and lossless sound pressure level spectra based on correcting measured data for various microphone heights. Microphone radial distance, 22. 86. Exhaust velocity, $301 \mathrm{~m} / \mathrm{sec}$.
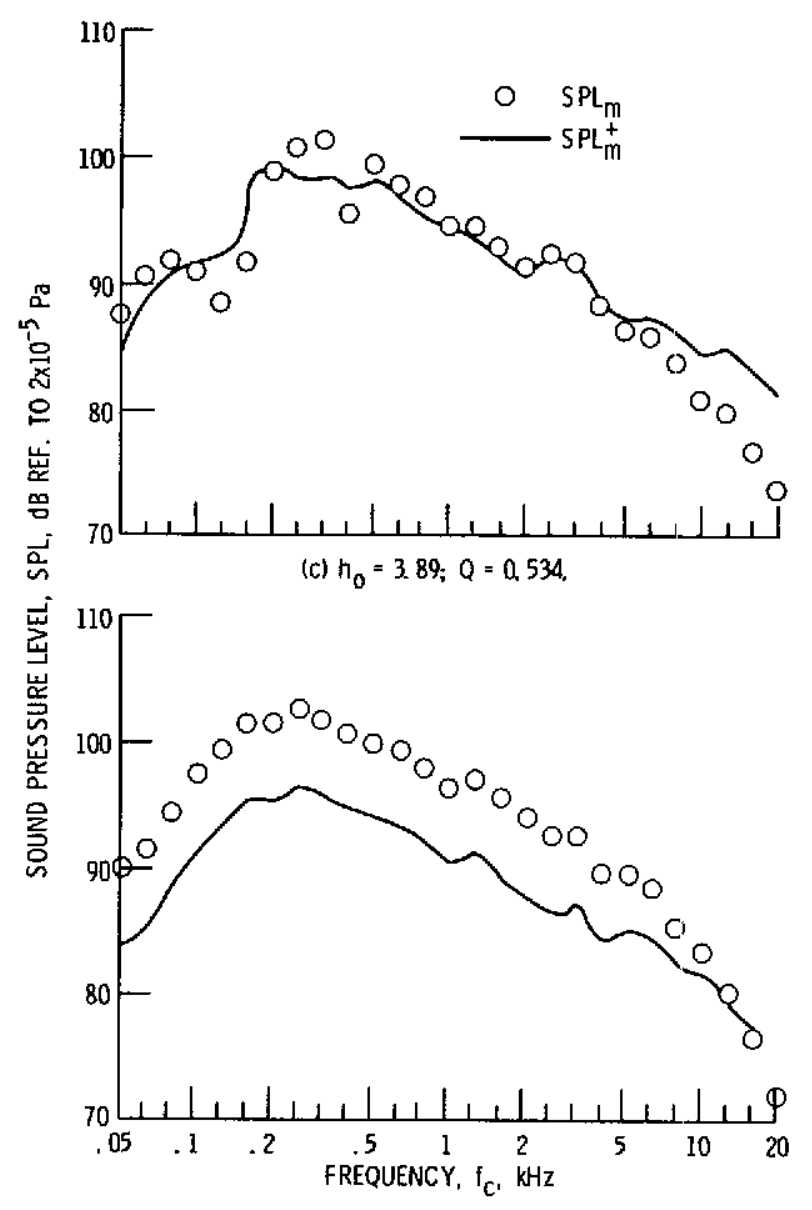

(d) $h_{0}=0.0061 \mathrm{~m} ; \mathrm{Q}=1$

Figure 6. - Concluded. 


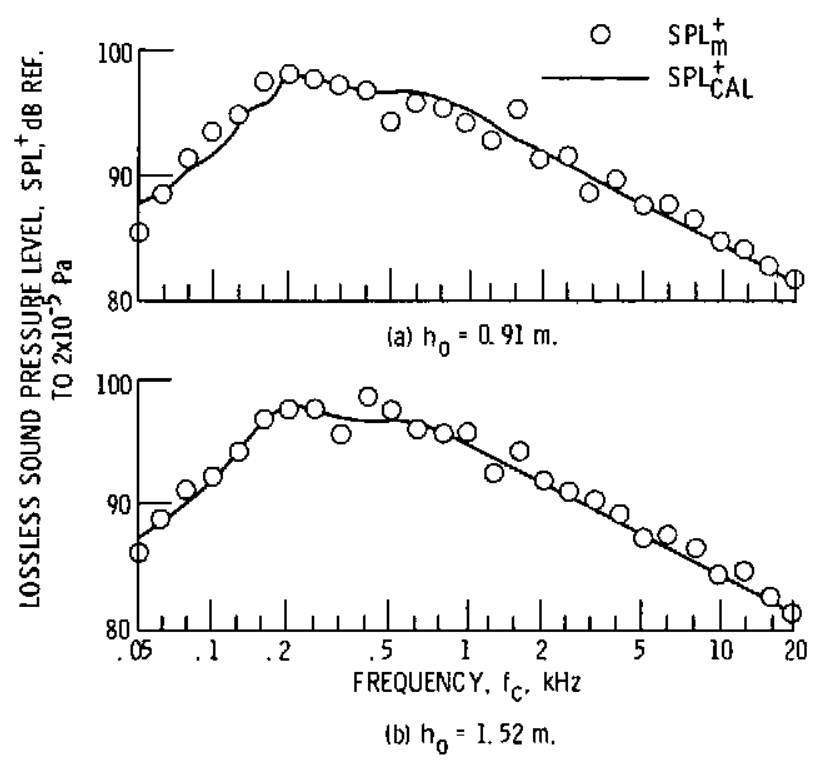

Figure 7. - Camparison of lossless sound pressure level based on measured data, $\mathrm{SPL}_{\mathrm{m}}^{+}$, and os calculated from curve fit, $S P L_{C A L}^{+}$. Microphone radial distance, $22.86 \mathrm{~m}$. Exhaust velocity, $301 \mathrm{~m} / \mathrm{sec}$.

MICROPHONE HEIGHT,

$\begin{array}{ll} & \text { h. m } \\ \square & 0.91 \\ \diamond & 1.52 \\ \triangle & 3.89\end{array}$

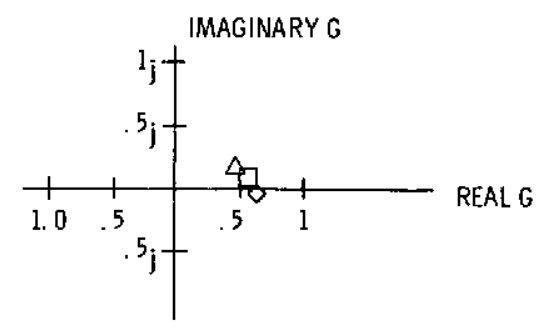

Figure 8. - Reflected signal transfer function, $G\left(t_{c}\right)$ for various microphone heights. Microphone radial distance, $22.66 \mathrm{~m}$. 


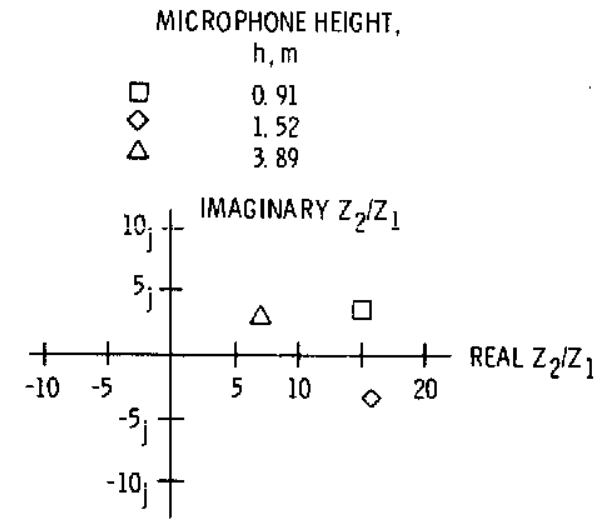

Figure 9. - Surface impedance relative to air, $Z_{2} / z_{1}$, for various heights. Microphane radial distance, $22.86 \mathrm{~m}$.
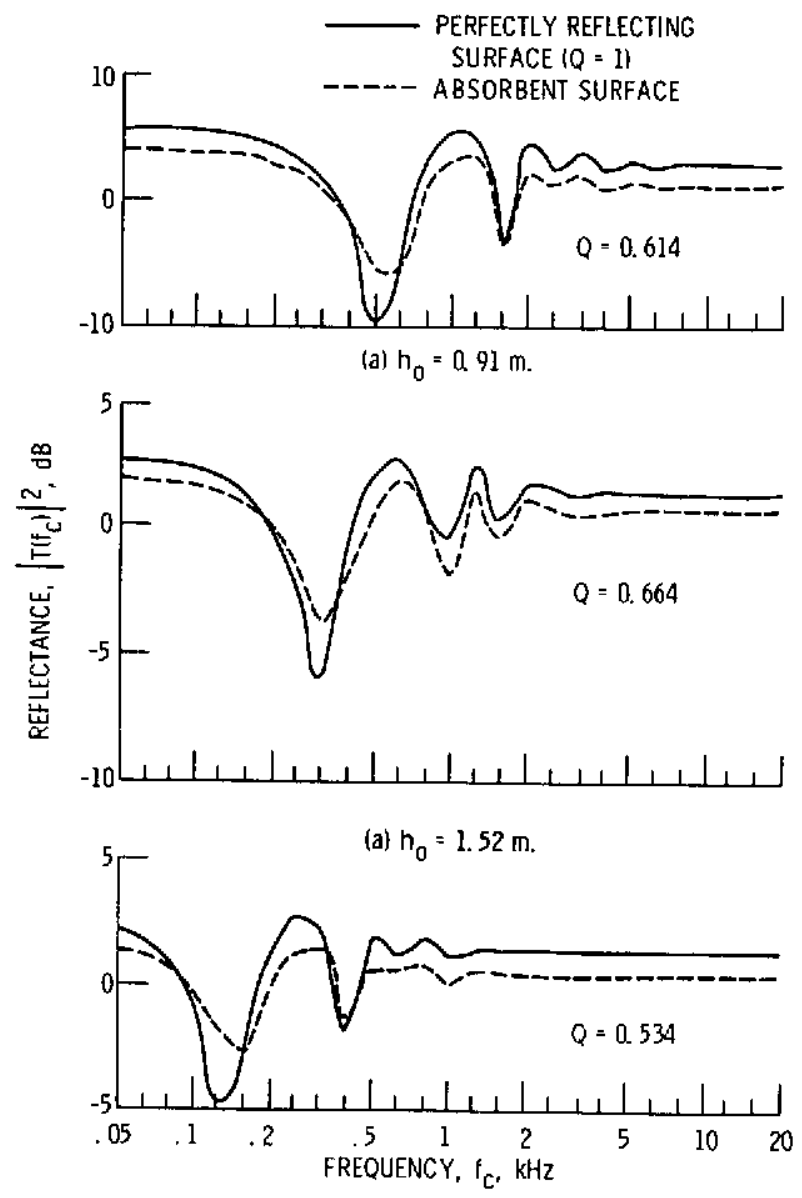

(c) $h_{0}=3.89 \mathrm{~m}$.

Figure 10. - Comparison of reflectance calculated for perfectly reflecting ground $(Q=1)$ with reflectance calculated by computer selected constants. Microphone radial distance from nozzle, $22.86 \mathrm{~m}$. 